\title{
Predictions of Structural Response to Dynamic Loads of Different Loading Rates
}

\author{
Hong Hao* \\ Centre for Infrastructure Monitoring and Protection, School of Civil \\ and Mechanical Engineering, Curtin University, Kent St., Bentley \\ WA6102, Australia
}

Received on 25 June 2015; Accepted 8 September 2015

\begin{abstract}
Owing to the increased terrorist bombing attacks, as well as accidental explosions associated with the rapid economic development and urbanization, more and more civilian structures might experience blast loadings in their service lives. These increase the demands of more structures being designed to resist certain level of blast loadings. As a result, some structural engineers with limited or no experience or training on structural dynamics nowadays might need to deal with analysis and design of structures against high-rate blast loads. Although design guides are followed, lack of fundamental knowledge of structural performance under high-rate loadings might not necessarily lead to accurate structural response predictions because the design guides normally only cover the most general and common blast loading scenarios and structural response conditions. Similarly, some researchers who have abundant experiences in analysis and design of structures under relatively low-rate dynamic loadings such as earthquake ground excitations intend to directly apply their experiences in earthquake engineering to blast resistant designs. This sometimes leads to inappropriate actions, e.g., adapting inter-storey drift as a performance criterion, using active control devices or cross bracing as a blast loading mitigation measure. This paper discusses the fundamental theory of structural dynamics, basic differences of structural responses subjected to low-rate dynamic and high-rate blast loadings. The accuracy of commonly used approaches in structural response analysis to blast loadings, i.e., the Single-Degree-of-Freedom analysis, will also be discussed.
\end{abstract}

Key words: dynamic response, earthquake, blast, loading rate, performance criterion 


\section{INTRODUCTION}

With rapid economic development and urbanization, accidental explosion events that caused significant damages to petrochemical industry facilities and residential structures, as well as loss of lives have been more and more frequently reported around the world. For example, an accidental explosion caused by gas leak occurred in an apartment building in East Harlem of Manhattan in New York City on March 12, 2014. The explosion leveled two apartment buildings, killing eight people and injuring at least 70 others [1]. Another example of accidental explosion occurred on July 6, 2013 at Lac-Mégantic, Quebec Canada, caused by a derailment of an oil shipment train. The oil shipment caught fire and exploded, killing 47 people and destroying more than thirty buildings along the railway line [2]. On the other hand, terrorism activities have been increasing around the world despite enormous efforts on war against terror. According to the US DoS Country report on terrorism, in 2012 a total of 6,771 terrorist attacks occurred worldwide, resulting in more than 11,000 deaths and more than 21,600 injuries [3]. This was increased to a total of 9,707 terrorist attacks, resulting in more than 17,800 deaths and more than 32,500 injuries in 2013, and among them, 57\% were related to bombing attacks [4]. These bombing attacks not only targeted on governmental buildings, but also on somewhat random civilian structures such as shopping centers and transportation structures. This imposes a great challenge on attack preventions since it is impractical to deny public access to these structures.

Owing to the increased numbers of explosion events, more structures might be subjected to blast loads in their service life. Therefore they need be designed to resist such loads for better protection of economy and life. This results in increased demands on capabilities of blast resistant analysis and design in structural engineering profession.

Traditionally, apart from some special structures such as those in petrochemical industry where accidental explosion is a potential hazard, civilian structures are not required to be designed to resist blast loads. Therefore there is generally a lack of engineers who have experiences in blast resistant analysis and design. In conventional undergraduate civil engineering curriculum in most universities around the world, structural dynamics is at most an optional subject. Even if there is a course that covers fundamental structural dynamics theory, usually it deals with dynamic loads from machine vibrations, earthquake ground motions and/or wind loads. A unit that covers blast resistant analysis and design of structures is very rare, even at the postgraduate level. Because of the increased demands on designing structures to resist blast loads, some practicing engineers with limited knowledge in structural dynamics might need to deal with structural designs against blast loads.

It is commonly understood that three dynamic loading parameters affect structural responses. They are the loading amplitude, duration and frequency. Similarly, three structural parameters, i.e., mass, damping and stiffness, affect structural capacity to resist dynamic loads. Blast loading has very high amplitude, extremely short duration and high frequency, as compared to earthquake and wind loads. Structures may behave very differently and have very different response and damage modes under high-rate blast the low-rate earthquake and wind loads. Therefore experiences gained in earthquake and wind engineering, although fundamental design philosophies, namely strength, ductility and energy absorption, etc, are the same, cannot be directly applied to the analysis and design of structures against blast loads.

This paper briefly introduces the fundamental structural dynamics theories, discusses the differences in structural responses subjected to earthquake and blast loads. Discussions on the limitations and accuracy of the commonly adapted simplified Single-Degree-of Freedom (SDOF) analysis, as well as blast loading estimations such as TNT equivalence approach in 
estimating blast loads from gas explosion will also be given. The primary objective of the paper is to highlight the fundamental nature and the uniqueness of structural responses to high-rate blast loads, so as to minimize the misunderstandings and errors in blast resistant analysis and design of structures.

\section{BLAST RESISTANT DESIGN CRITERIA AND GUIDES}

There are in general two types of design considerations, namely the design of structural members to be blast-resistant, and the design of structures for integrity, i.e., prevention of structural progressive collapse. In reality, direct explosion effect is often limited to the area near the explosion center. Blast loads may cause certain level of damage to structural components only in the close proximity of the explosion. Structural members can be properly designed or strengthened to resist the given blast loadings. In practice, reliable predictions of blast loading levels on structures, especially on commercial structures where protective perimeter is not a proper solution for structure protection are often not possible because the location and quantity of explosion are unknown. Consequently designing all the critical structural components such as gravity load-carrying columns as blast-resistant would not be possible and uneconomical. In such cases, structures should be designed to meet the integrity requirements with sufficient strength and redundancy so that loss of one or a few components does not lead to a disproportionate collapse of the remaining structure.

Many requirements are available for different design considerations. Most of them are qualitative and descriptive only. For example US DoD Minimum Antiterrorism Standards for Buildings [5] specifies the minimum standoff distances for buildings with conventional constructions and hardened structures at different protection levels. Requirements of specific considerations on window designs and prevention of progressive collapse are stated. Similarly US Interagency Security Committee (ISC) Security Design Criteria [6] requires structural members and windows of US Government Buildings being able to resist certain level of external and internal blast loadings, depending on the required protection levels, and progressive collapse must be prevented in any cases. Other guides that give blast resistant design criteria include FEMA 430 [7], FEMA 428 [8], FEMA 426 [9], FEMA 427 [10], NATO AASTP-1 [11], etc.

Other design guides define methodologies for estimating blast loads and analysis and design of blast-resistant structures [11-18]. Among them UFC 3-340 02-2008 [12] is probably the most commonly used guide in designing civilian structures against blast loadings. It gives charts to estimate blast loads on structures at different standoff distances and subjected to different quantities of TNT equivalent explosions. Structural responses are analyzed based primarily on equivalent SDOF systems derived with assumption of flexural response mode. Design charts given in the guides are derived mainly based on SDOF analysis with the assumption of elastic-perfect-plastic response function. The design criteria are defined also based primarily on the flexural governed responses. These defined approaches and charts may give reliable predictions of structural responses subjected to relatively far-field explosions when structure experiences primarily flexural responses. In many situations, as will be discussed in the subsequent sections, they may not lead to accurate predictions of blast loads on structures and structural responses, as well as rational assessment of structural damages.

Similarly the design guides for analyzing structural integrity to prevent progressive collapse are based mainly on static or approximate dynamic analyses of structural stability under gravity loads after removing one or a few vertical load-carrying components $[17,18]$. These approaches again may not give accurate predictions of 
structural progressive collapse responses. Indeed structural progressive collapse usually occurs after the action of blast loads because of their very short duration. However, if blast loads are large enough to destroy some structural columns, they very likely also cause certain damage to adjacent structural components. Moreover, large amount of blast energy would have been imparted into the structure. In other words blast-induced progressive collapse is not likely to start with all the structural components, besides those few being removed, intact without any damage and zero initial conditions [19].

Therefore proper understanding of the limitation and applicability of the design guides is essential for safe and economic designs of structures against blast loads.

\section{BLAST LOADS ESTIMATION}

Like UFC 3-340 02-2008 [12], design guides provide charts for estimation of blast loads on structures. The charts are constructed usually based on field blasting test data and the blast loads are determined with respect to the scaled distances. Since blasting tests were often conducted in open field, directly applying the charts given in the design guides may not lead to accurate predictions of blast loadings on structures in complex environment. For example explosion shock wave interaction with surrounding structures in a city environment, as well as interactions with structures with irregular surfaces such as sharp corners and convex surfaces etc will result in significant changes in shock wave propagation and hence blast loadings on structures as shown in Figure 1 obtained by Gebbeken and Doge [20].

Similarly blast loading on structures behind a blast barrier is very different from that on walls directly facing the explosion center as shown in Figure 2 [21], which cannot be reliably predicted by following the charts given in design guides either.

Besides blast loads from chemical high explosives, typical petrochemical industry accidental explosions include vapor cloud explosion (VCE), pressure vessel explosion, gas explosion and dust explosion [15]. In general three approaches are used to predict blast loads from these industry explosions, namely TNT equivalence [15], Baker Strehlow Curves [22] and the TNO1985 Multi-Energy Method [23]. These approaches in general can be used to predict peak overpressure for far field explosion which is over 30 meters from the explosion center. It was found that the TNT equivalent method should not be used when the estimated gas explosion overpressure is higher than 1 bar (i.e. $101.3 \mathrm{kPa}$ ) [24]. Similar observation was also made that a single equivalence factor may be valid only when the overpressure is less than 1 bar (i.e. 101.3 kPa) for the far field explosion [25].

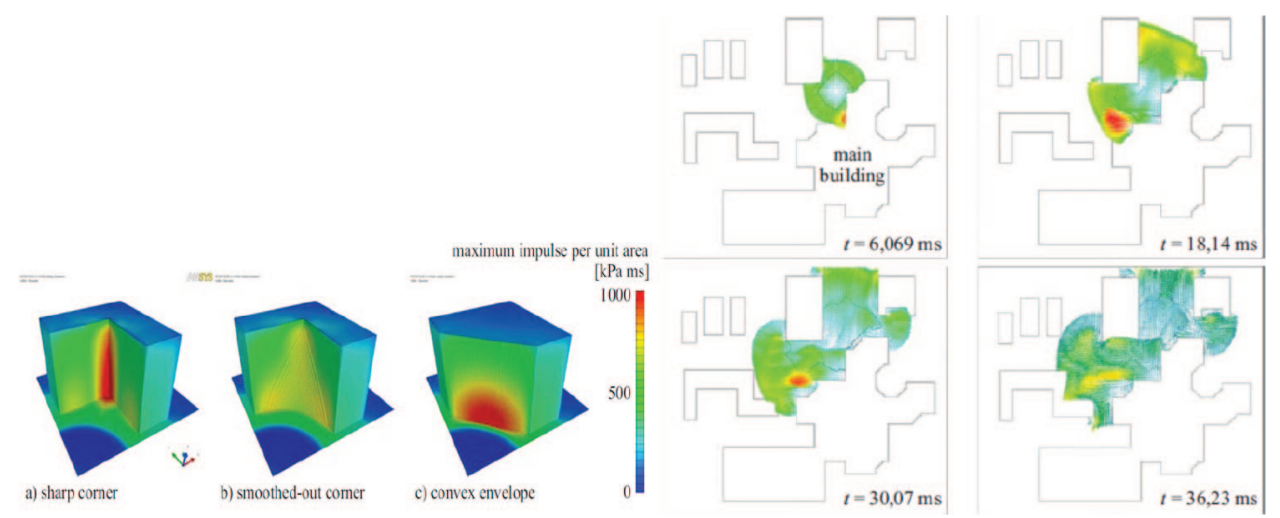

Figure 1. Shock wave propagation and interaction with structures (from (20)) 

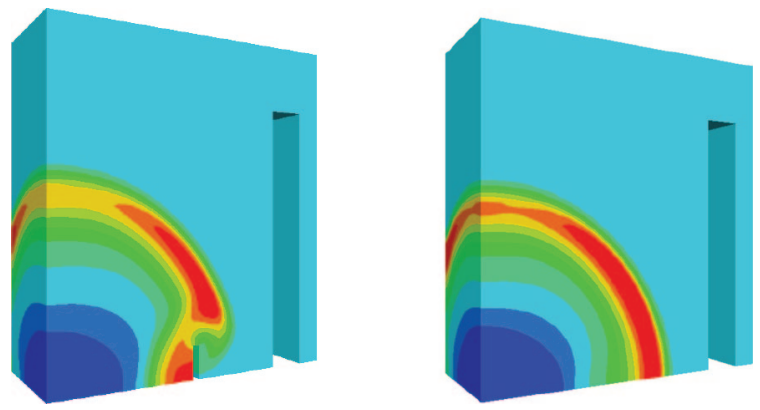

Figure 2. Simulated shock wave propagation and interaction with a blast barrier (21)

Therefore when calculating blast loads in complex environments and from near field industry explosions, computational fluid dynamics (CFD) models are required to predict overpressures with a sufficient accuracy. Directly applying charts given in design guides based on idealized conditions and environments may not lead to reliable predictions.

\section{CHARACTERISTICS OF STRUCTURAL RESPONSES SUBJECTED TO BLAST AND EARTHQUAKE LOADS}

Without loss of generality, response of a SDOF system subjected to a triangular load as shown in Figure 3 is employed here to illustrate the fundamental nature of structural response to blast loads.

For the system shown in Figure 1, neglecting viscous damping, the dynamic equilibrium equation is

$$
m \ddot{v}+k v=P(t)
$$

in which $m$ is the mass and $k$ is the stiffness of the system, $v$ is the displacement response; $m \ddot{v}$ is the inertia resistance and $k v$ is the elastic resistance; and $P(t)$ is the dynamic load with peak $P_{0}$ and duration $t_{d}$. Assuming zero initial conditions, the solution of the above ordinary differential equation can be straightforwardly obtained as,

$$
v(t)=\left\{\begin{array}{lr}
\frac{P_{0}}{k}\left(\frac{\sin \omega t}{\omega t_{d}}-\cos \omega t-\frac{t}{t_{d}}+1\right) & 0 \leq t \leq t_{d} \\
\frac{\dot{v}\left(t_{d}\right)}{\omega} \sin \omega t+v\left(t_{d}\right) \cos \omega t & t>t_{d}
\end{array}\right.
$$
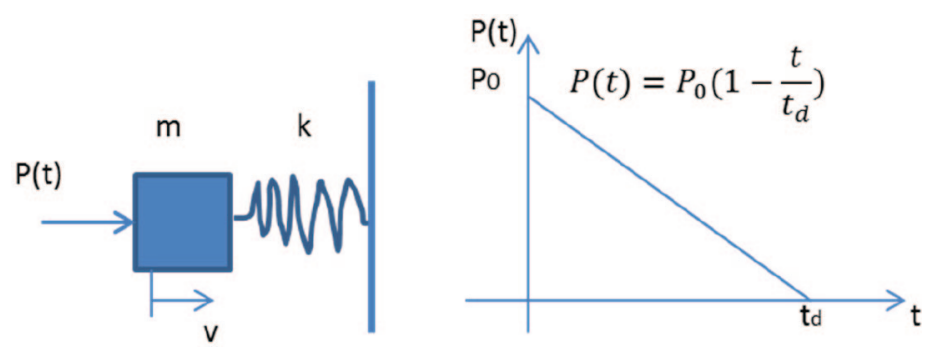

Figure 3. SDOF system subjected to a triangular impulse 
where $\omega=\sqrt{k / m}=2 \pi f=2 \pi / T$ is the circular vibration frequency of the SDOF system, in which $f$ is the vibration frequency and $T$ the vibration period. Differentiate the displacement twice with respect to time $t$, the acceleration response is

$$
\ddot{v}(t)=\left\{\begin{array}{lc}
\frac{P_{0}}{k}\left(-\frac{\omega}{t_{d}} \sin \omega t+\omega^{2} \cos \omega t\right) & 0 \leq t \leq t_{d} \\
-\omega \dot{v}\left(t_{d}\right) \sin \omega t-\omega^{2} v\left(t_{d}\right) \cos \omega t & t>t_{d}
\end{array}\right.
$$

Closely examining the above closed-form solution reveals that at $t=0$, the displacement response is zero, implying there is no elastic resistance, and $P_{0}=m \ddot{v}(0)$, indicating the blast load is completely resisted by inertial force. When $t$ is small, i.e., in the early stage of structural resistance, the displacement and elastic response are very small. The structure experiences only minimum movement and the blast load is balanced primarily by inertial resistance. This observation can be extended to the entire blast loading duration if $t_{d}$ is small compared to the structural vibration period $T$, which is often the case for most practical structures and blast loading scenarios, except those associated with confined explosions.

The above solutions demonstrate the importance of inertia resistance to blast load. This is because blast loading duration is short. In theory, a dynamic load generates structural acceleration response first, and structural displacement is always lagged behind with a phase difference. In other words, when a dynamic load is suddenly applied to a structure, the structural response sequence is acceleration first, followed by velocity and then displacement. In the initial response stage, displacement response is small. Since blast loading duration is short, it may end before structural displacement picks up. Therefore blast loads are often resisted primarily by structural inertial resistance. This observation indicates increasing structural mass is beneficial for blast loading resistance.

The above observation is different from structures under earthquake loadings, where elastic resistance is more critical and increasing structural mass attracts more seismic force. Under seismic ground excitation, the structural response equation is

$$
m \ddot{v}+c \dot{v}+k v=-m \ddot{v}_{g}
$$

where $c$ is the viscous damping ratio and $\ddot{v}_{g}$ is the ground acceleration. As can be noted, seismic load is directly proportional to the structural mass, indicating increasing structural mass results in larger seismic forces; therefore it is not beneficial to seismic resistant design.

Moreover, seismic ground excitations usually last a few seconds to more than one hundred seconds, longer than vibration periods of most structures. Therefore it has sufficient time for structural velocity and displacement to build up and damping resistance, $c \dot{v}$, and elastic resistance, $k v$, become important and often dominate in seismic loading resistance. Seismic ground motion frequency content is typically in an order of $0.5 \mathrm{~Hz}$ to $25.0 \mathrm{~Hz}$, vs hundreds to thousands $\mathrm{Hz}$ of blast loading, which also results in very different response characteristics of structures subjected to earthquake and blast loads. Figure 4a shows a typical Fourier spectrum of a recorded ground motion in 2011 Christchurch earthquake in New Zealand. As shown, most ground motion energy concentrates in a frequency band less than $10.0 \mathrm{~Hz}$, which will excite the first few modes of structures as shown in Figure 4b. As a result, the structural responses are often displacement, or storey-drift governed as shown in Figure 4c. 


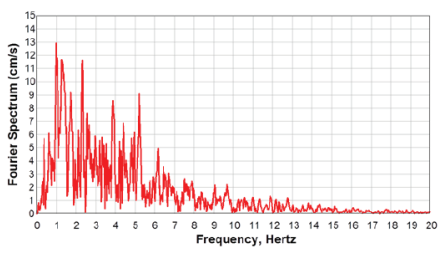

(a)

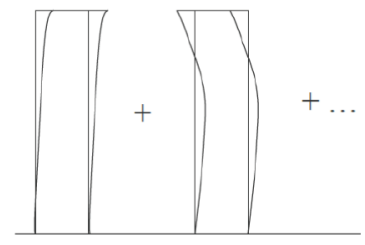

(b)

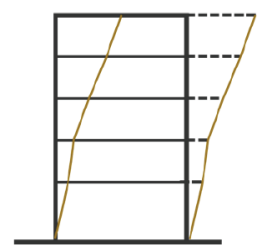

(c)

Figure 4. (a) Typical earthquake ground motion Fourier spectrum; (b) low structural response modes and modal superposition; (c) typical drift governed structural response mode subjected to earthquake loads

In other words, earthquake ground motion usually excites the fundamental and low structural vibration modes. Structural response is global. The damage criteria are therefore displacement response related, such as ductility ratios and inter-storey drift. For example, the Australian Earthquake Loading Code specifies 1.5\% inter-storey drift as the allowable response level in structural design against earthquake loading [26]. Since the design criterion is 'life safety' and 'collapse prevention', this inter-storey drift associates to the collapse of the structure. Other seismic codes may use different inter-storey drift level. For example, Structural Engineers Association of Northern California (SEAONC) limits the inter-storey drift level to $2.5 \%$ for prevention of structural collapse for ductile structures in California [27].

Under blast loading, although progressive collapse might be induced after the loss of some vertical load-carrying members owing to the insufficient alternative load paths, direct structural response to blast loads is mainly local as shown in Figure 5. Owing to large mass at floor levels, which generate large inertial resistance to blast load, the response at the floor level is therefore small. The structural damage is mainly associated to structural component damage, which in turn might lead to progressive collapse if sufficient numbers of vertical load-carrying members are lost. Obviously the displacement-related damage criteria developed in earthquake engineering cannot be used to assess the performance of structures under blast loading. Under blast loading, a structure might experience severe damage, even total collapse at very small inter-storey drift or even no inter-storey drift. Using inter-storey drift as a criterion to assess the structural damage of frame structures under blast loading, as did by some researchers, will lead to obviously incorrect conclusions.

Figure 6 shows the typical structural damage modes induced by earthquake and blast loads. It is obvious that the structures subjected to earthquake loads experienced excessive drift, which induced structural collapse. Under blast loading, however, although excessive structural damage occurred, no obvious structural drift can be observed. The progressive structural collapse was triggered by damage of a few vertical load-carrying structural members.

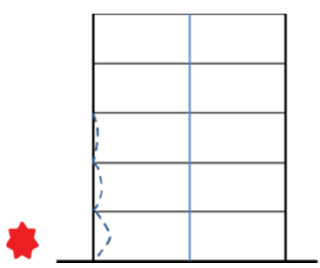

Figure 5. Localized response mode of structures subjected blast loads 

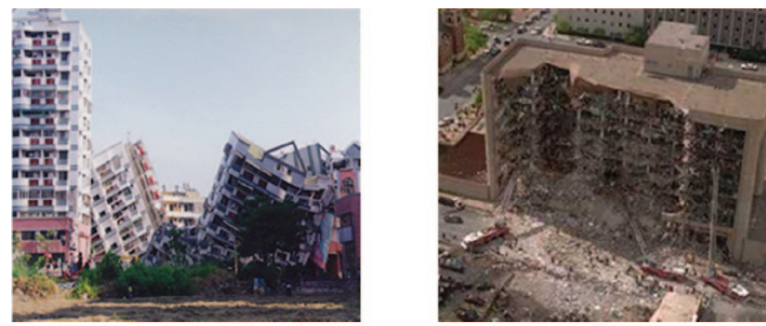

Figure 6. Typical structural collapse modes (a) subjected to earthquake loading; (b) blast loading

The above discussions demonstrated the different response and failure modes of structures under earthquake ground motion and blast loads. Because of these differences experiences in earthquake engineering cannot be directly applied to blast response analysis and design. Also because of these differences, techniques that work fine to mitigate earthquake loading effects, such as using cross bracings in frame structures as shown in Figure 7, is not necessarily an appropriate choice for mitigating blast loading effect. Bracing increases the structural global stiffness. Yielding of bracing members under cyclic earthquake excitations absorbs significant amount of seismic energy, therefore it is a simple and economic measure to strengthen structures to resist earthquake loading. However, bracing is only effective in controlling the global responses. Therefore it is not effective for mitigating the blast loading effect when structural response is governed by local response mode. It is effective only when the structural

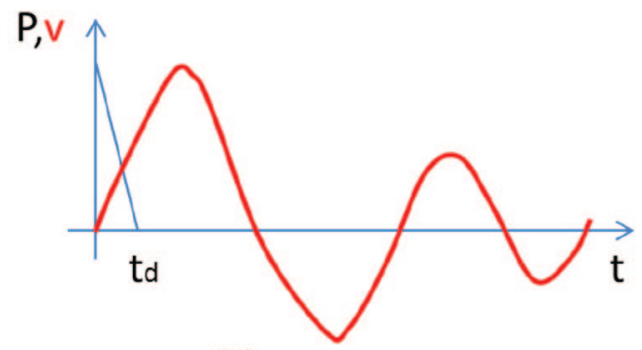

(a)

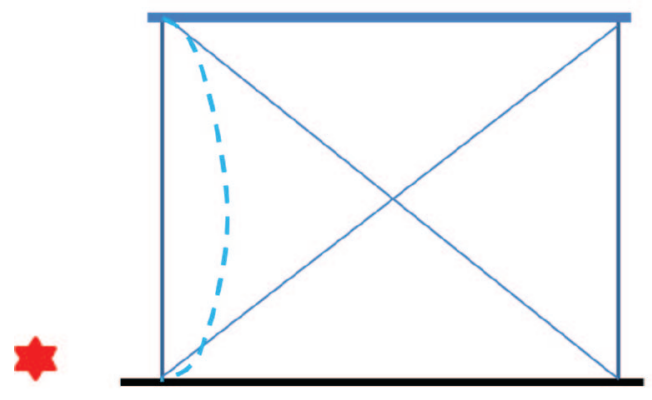

(b)

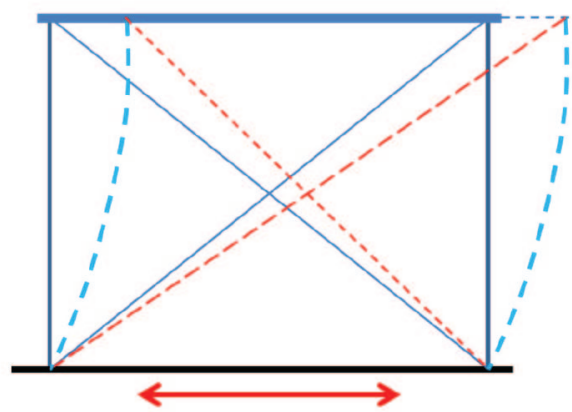

(c)

Figure 7. Response modes of braced frame structures, (a) blast load and response time history; (b) local response mode during blast loading phase $\left(t<t_{d}\right)$; (c) global vibration mode during free-vibration phase $\left(t>t_{d}\right)$ or under earthquake ground excitation 
response is governed by global response mode in the free vibration phase, i.e., the structure is ductile and survives the direct blast loading impact.

The above discussions demonstrate that under blast loading, the structural resistance comes primarily from inertial resistance as displacement response is small and elastic resistance needs time to develop. Subjected to high-rate blast loading, a structure, even a flexible one might fail at small displacement, the response mode and damage mechanism are very different from those under static and low-rate dynamic loads. Deformation-based performance criteria developed in earthquake engineering such as storey drift cannot be directly applied to assess structural performance under blast loading, where very small storey drift may be associated with significant structural damage. Adding mass is always beneficial to increase the structural blast loading resistance capacity owing to inertial resistance, but should be avoided in earthquake engineering since adding mass increases seismic force on structures. If a structure is designed to resist both earthquake and blast loads multi-Hazards analysis should be performed. However, increase structural strength, ductility and energy dissipation capability is always beneficial irrespective of the loading conditions.

\section{LIMITATION OF SDOF ANALYSIS}

In blast-resistant design analysis, there are three approaches, namely the equivalent static load (ESL) approach; single-degree-of-freedom (SDOF) approach and numerical simulations. The equivalent static load (ESL) approach can be used for predicting the responses of structural connections and very stiff structural members such as shear walls. However, it is well acknowledged that ESL is accurate only when the dynamic load is slow compared to the structural response time (period), i.e., $t_{d}<<T_{n}$, so that the inertial effect is small as compared to elastic effect. Many numerical methods have been developed to reliably predict structural responses and damage. These include finite element method, discrete element and meshless mothed, etc. It has been proven that if properly used, numerical approach can well predict the structural responses and damage subjected to blast loads. The challenge of using numerical prediction is that it is very time consuming, even with modern computer technology, it is still often beyond the affordability of normal consulting offices. Moreover, the accuracy of numerical predictions depends on the availability of detailed dynamic material models, which are sometimes not available. It also requires profound understandings of the computational mechanics, damage mechanics and structural dynamics. In this paper, the discussion will be concentrated on the most commonly used analysis approach, i.e., SDOF analysis.

SDOF analysis is the most widely used dynamic analysis method for designing and analyzing structural components subjected to blast loads because of its simplicity and the ability of including dynamic effect in the analysis, also because it is the method detailed in the most popular blast analysis and design guides (e.g., UFC 3-340-02, 2008 [12] and ASCE, 2010 [15]). The method was initially introduced in the textbook by Biggs in 1964 [28]. It idealizes the structural component as a SDOF system with an equivalent spring, mass and dynamic load.

Taken a simply-supported beam shown in Figure 8 as an example, assuming the deflection shape $\phi(x)$ is known, one only needs to calculate the response amplitude $v$ to fully determine the response of the structure under blast load $P$. The equivalent SDOF is developed to calculate response $v$. According to the derivation in [28], the equivalent mass $M e$, spring stiffness $\mathrm{Ke}$ and equivalent load $\mathrm{Pe}$ can be determined by

$$
M_{e}=\int_{0}^{L} \rho \phi^{2}(x) d x
$$



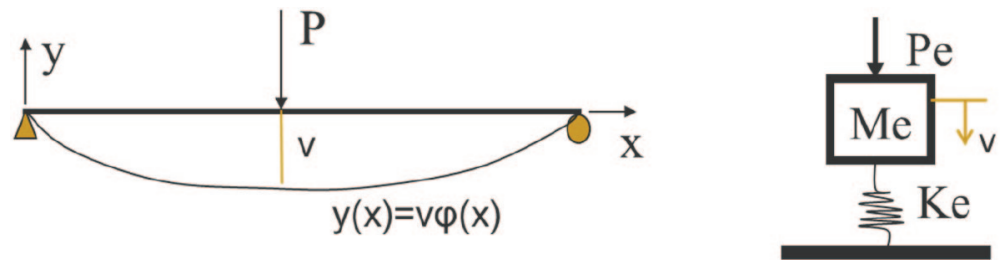

Figure 8. Idealize a structural component to an equivalent SDOF system

$$
\begin{gathered}
P_{e}=\int_{0}^{L} P(x) \phi(x) d x \\
K_{e}=K_{L} K=\frac{P_{e}}{P_{t}} K
\end{gathered}
$$

where $\rho$ is the mass density of the structure per unit length, $P_{t}$ is the total load applied on the structure, $K_{L}$ is the load factor, $K$ is the stiffness of the structure corresponding to the displacement $v$ and loading configuration. As can be noted, the equivalent parameters (mass, stiffness and load) depend on the deflection shape $\phi(x)$. Assuming flexural deflection shape, i.e., the deflection shape of the structure under the same loading configuration as the applied blast load but static, the load factor, mass factor (equal to $M e / M t$ and $M_{t}$ is the total structural mass) have been derived and given in $[12,15]$ for typical loading configurations (uniform and concentrated) and structural boundary conditions (pinned or fixed). Because flexural response shape is assumed, the equivalent SDOF analysis approach given in [12, 15] is therefore appropriate for far-field detonation scenarios where the blast loading is most likely uniform on the structure and the primary response mode is most likely flexural. Oswald and Bazan [29] compared the blast testing data on corrugated steel panels, reinforced concrete walls, one-way reinforced masonry walls, and two-way unreinforced masonry walls with SDOF analyses. The testing data included in the comparison all have sufficient information to completely define the equivalent SDOF system for the structure, the applied blast load, and the measured maximum dynamic deflection. In the SDOF analysis, modifications are made if the structural and blast loading conditions are not the same as those used in deriving the equivalent SDOF system in $[12,15]$. These include using the "equivalent" uniform blast load that has the same work energy as the actual blast load as specified in $[12,15]$, and account for non-flexural modes such as compression and tension membrane effect [30]. With all these considerations, it is found that the SDOF analysis yield accurate enough predictions for design purpose. The ratio of the SDOF analysis result to testing result ranges from 0.42 to 2.82 , but the average ratio for all the 129 tests considered in the comparison study is 1.17 with a standard deviation of 0.41 . These results indicate that SDOF approach in general over predicts structural responses by $17 \%$, and it could significantly underestimate ( $42 \%$ of the measured response) or overestimate (282\%) the recorded responses. It should be noted that these results were obtained by experienced engineers who have abundant experiences in blast resistance analysis, and the equivalent SDOF systems were derived according to the testing conditions, instead of directly following the values given in the design guides. For example, in their analyses, non-uniform blast loading and non-flexural modes are considered [29]. If the analysis were carried out by directly following the procedure and parameters given in UFC 3-340-02 [12] without considering these variations, more significant prediction errors of the structural responses would be expected. Below discusses some typical limitations of SDOF approach. 


\subsection{UNIFORM LOADING ASSUMPTION}

The load factor is derived by setting the external work done by the equivalent load $P_{e}$ on the equivalent system equal to the external work done by the actual load $P_{t}$ on the actual element deflecting to the assumed deflected shape. The load factors given in the charts in [12] are derived based on uniform or concentrated loading conditions. For other loading conditions, e.g., loading conditions shown in Figure 9, which are not defined in UFC, the equivalent load can be calculated by Eq. (5) with the deflection shape corresponding to the static elastic deflection shape of the structure under the same loading distributions, and the load factor is defined as $P_{e} / P_{t}$.

\subsection{RESPONSE MODES AND DEFLECTION SHAPE}

Depending on the blast loading amplitude and the ratio of blast loading duration to the fundamental vibration period of the structure, $t_{d} / T$, the primary structural response and damage mode could be very different. In general, when $t_{d} / T$ is very small, the structural response is mainly associated with stress wave propagation and structural mass plays an important role in resisting the blast loads; when $t_{d} / T$ is large, the response is quasi-static and structural stiffness governs the response; when $t_{d}$ and $T$ are comparable the response is dynamic and in such cases structural mass, stiffness and damping all significantly affect structural responses. Figure 10 shows the respective structural response and damage modes corresponding to different explosion conditions. As shown in Figure 10a, when the explosion center is close to a reinforced concrete structure so that the blast loading duration $t_{d}$ is very short, the structural damage is governed primarily by local concrete crushing and spalling due to stress wave propagation. There is no global structural response. Therefore the SDOF analysis, which is developed with global structural response assumption, is not applicable to predict this type of structural responses. Increasing the $t_{d} / T$ ratio, the structural response and damage could be governed primarily by direct or diagonal shear responses as shown in Figure 10b and 10c. In these cases, direct application of the parameters from [12] for the equivalent mass, stiffness and load will not lead to accurate predictions of structural responses. However, if the modified deflection shape $\phi(x)$ is used to realistically represent the structural response in deriving the equivalent SDOF parameters as defined in Eqs. (4) to (6), improved prediction accuracy can be achieved. When $t_{d} / T$ is relatively large, the response is usually governed by flexural mode as shown in Figure 10d. In this case, the SDOF procedure
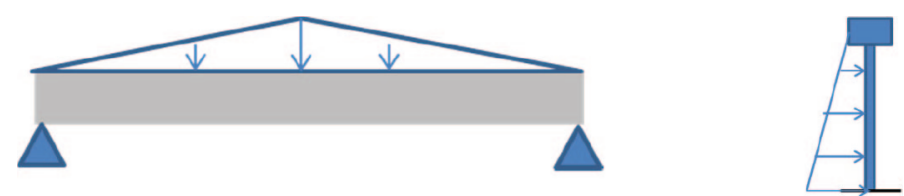

Figure 9. Examples of non-standard loading distributions

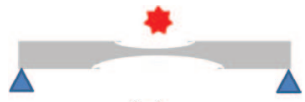

(a)

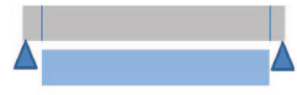

(b)

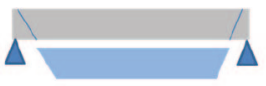

(c)

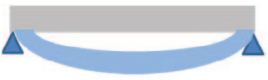

(d)

Figure 10. Typical failure mode of a structure member subjected to blast loads 
given in [12] leads to good predictions of structural responses because it is derived with flexural response assumption. In other words, the parameters given in the design guides are derived based on flexural response assumption. When the structural responses are governed by other response modes, modifications are needed in deriving the equivalent SDOF. Otherwise the SDOF analysis will not lead to accurate structural response predictions.

Moreover, because of the short blast loading duration, the peak structural response often occurs during the free vibration phase, i.e, after the action of blast loading if the structure survives the impact of blast loads. This may impose some difficulty in selecting a proper response shape in deriving the equivalent SDOF system. As shown in Figure 11, considering a rigid floor supported by two ductile columns, its initial response mode is dominated by local element mode owing to large inertial resistance from the lumped mass at the floor level. The dominant response mode will be quickly changed to global mode as structural vibration continues in free vibration phase. For such situations, the SDOF method developed using deflection shape based either on the local element or global response mode will not give a complete representation of the true characteristics of structural responses. If local response mode is assumed in deriving the equivalent SDOF system, the equivalent mass and stiffness, and hence the vibration frequency of the system is incorrect when structural response and damage occur in the free vibration phase. On the other hand, if global response mode is assumed in deriving the equivalent SDOF system, the equivalent blast load, and the structural response in the forced vibration phase will not be accurately predicted. In such cases, the accuracy of predictions can probably be improved by performing two-step calculations. In the first step, the equivalent SDOF system is derived according to the local response mode to calculate the responses in the forced vibration phase, the responses at the end of the forced vibration phase are then used as the initial conditions in the second-step calculations of the free vibration responses with the equivalent SDOF system derived according to the global response mode assumption.

\subsection{RESISTANCE-DEFLECTION FUNCTION}

The design charts given in $[12,15]$ are based primarily on elastic-perfect-plastic resistance function assumption as shown in Figure 12. They work well when the structural response is mainly elastic-plastic. However, for some cases, the resistance-deflection relationship of a structure, especially a composite structure, cannot be well modelled by an elastic-perfectplastic relation. Figure $12 \mathrm{~b}$ shows a typical resistance-deflection function of a laminated glass panel with a PVB interlayer. As shown, the structural resistance and stiffness are governed by glass pane before glass cracks. After glass cracks, the resistance and stiffness drop quickly, and the resistance is provided by the PVB layer, which is very ductile. For a

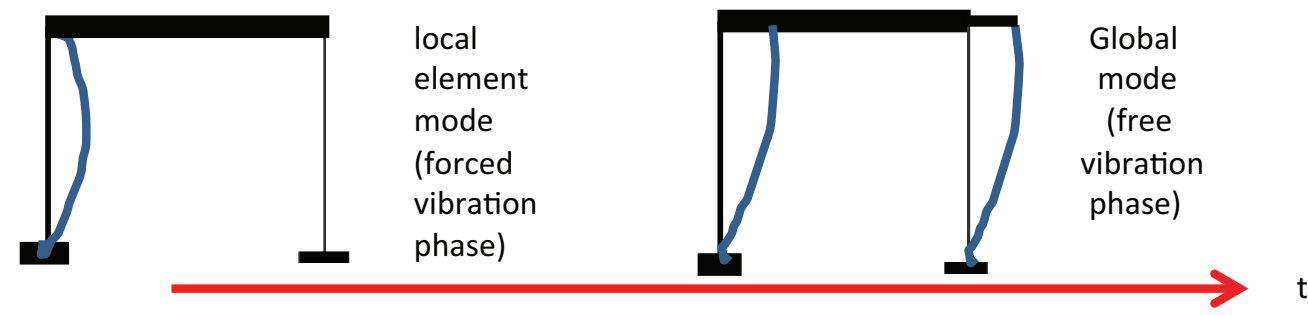

Figure 11. Changing the dominant response mode of a structure subjected to blast loading 

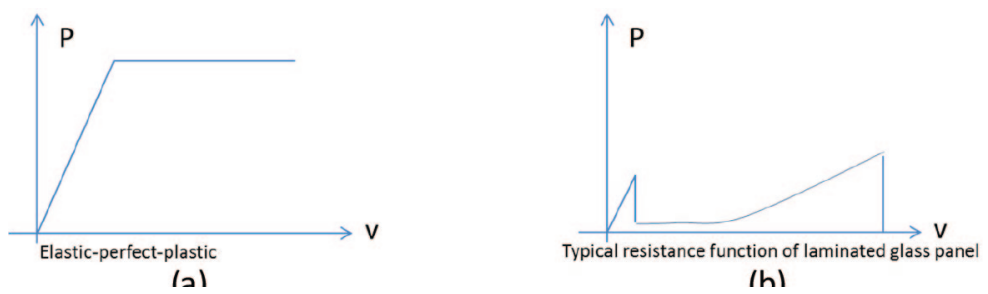

Figure 12. Different resistance-deflection functions

structure with such a resistance function, direct use of the design charts given in [12] will not give reliable structural response predictions.

\subsection{DESIGN CRITERIA}

Because the design guides given in [12] are developed based on the flexural response mode, the corresponding design criteria are based on the structural displacement rather than the allowable stress. Figure 13 from UFC defines the allowable deflections of structural members for design at different levels. They are based on ductile response assumption, therefore not applicable when the response is non-ductile, i.e., shear response governed, and not applicable when the structural response and damage are governed by localized concrete crushing and spalling due to stress wave propagation inside the structural member as shown in Figure 10a.

\subsection{POSSIBLE ERRORS IN USING EQUIVALENT SDOF ANALYSIS}

The limitations of the design charts given in [12] are discussed above. Because it is probably the most comprehensive guide for blast resistance analysis and design and is freely available to every interested individual, UFC is most popularly used in design practice. Owing to a lack of profound understanding of the unique characteristics of structural responses subjected to blast loading, some users simply follow the procedures and take the values from the charts without taking into consideration the differences in blast loading conditions and structural response modes. These lead to some prediction and design errors.

Following are two examples in reference [31] that discusses the prediction errors of using SDOF analysis. In the first example, the response of a steel column to a blast load generated from a $600 \mathrm{~kg}$ of TNT explosion on ground surface at $3 \mathrm{~m}$ is calculated using three approaches, namely: a SDOF model, a FE model with nonlinear beam elements, and a continuum model with shell elements. The column is fixed at its base and pinned at the top. The detailed FE model simulation captured some localized panel zone yielding and flange

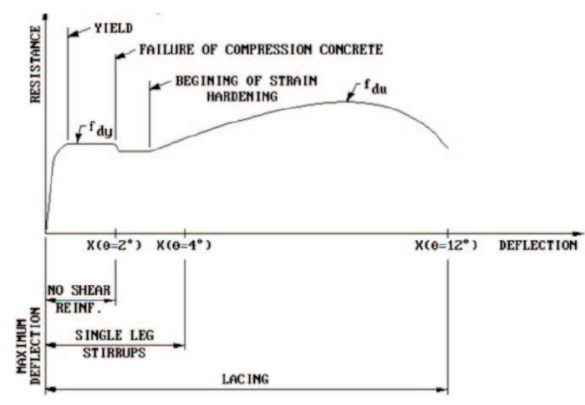

Figure 13. Deflection-based design criteria from (12) 
folding at the column's base as shown in Figure 14a. These localized damages, which absorb blast loading energy and affect the column responses, could not be captured by either the beam or the SDOF model. As shown in Figure 14b, the detailed FE model simulation and the simplified SDOF analysis give very different structural response predictions.

The second example presented by the authors in [31] is the prediction results of three steel columns of different section shapes but having similar section moduli as shown in Figure 15a. The three columns are subjected to the same blast loading. Because the flexural rigidities of the three columns are the same, which lead to the same SDOF system, therefore the SDOF predictions will be the same. However, the detailed FE model simulations yield very different responses, as shown in Figure 15b, since the local sectional responses of the three columns are very different, which cannot be captured by the simplified SDOF analysis.

These two examples demonstrate the influences of local responses such as local buckling of cross section on responses of structural elements, which cannot be modelled by the equivalent SDOF system. Therefore special attentions should be paid when local damage of the structural element section under blast loading is likely.

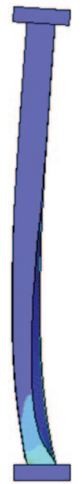

(a)

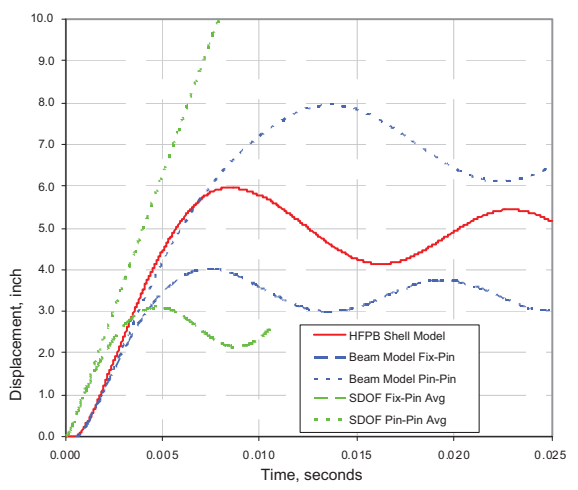

(b)

Figure 14. Fixed-pinned column response to blast load obtained by different methods (from (31))

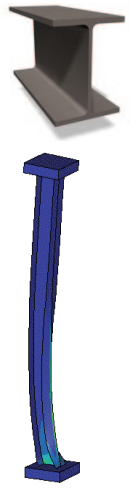

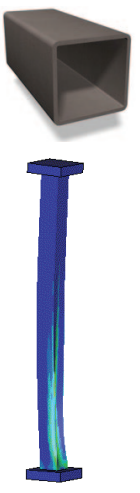

(a)
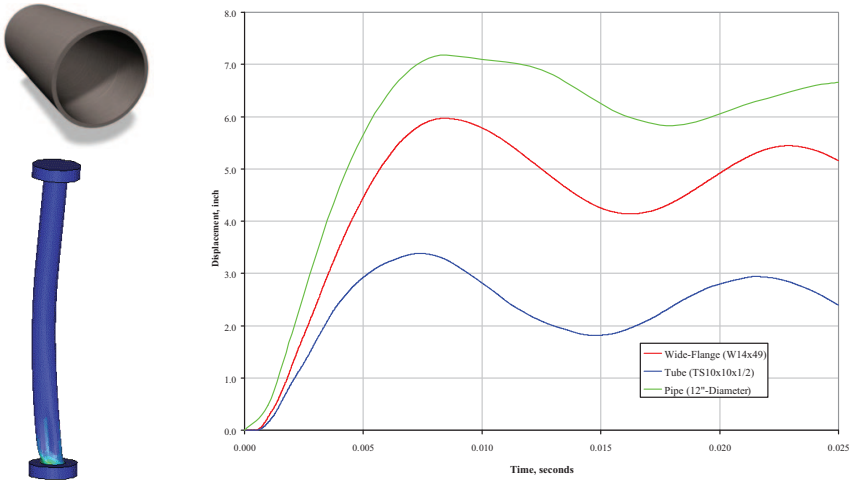

(b)

Figure 15. Responses of three steel columns of different sections but the same sectional moduli (31) 
Results from a recent experimental study also demonstrate the inaccuracy of predictions based on the SDOF approach. In the field blasting tests a dozen of monolithic glass windows of dimension $1.5 \mathrm{~m} \mathrm{x} 1.2 \mathrm{~m}$ and different thicknesses subjected to blast loads of different charge weights and standoff distances were tested [32]. Before the tests, black dots were marked on glass window specimens. Two high speed cameras were used to track the deformation of the glass window specimens. Figure 16 shows the high-speed camera images of a $6 \mathrm{~mm}$ thick glass window subjected to a $5 \mathrm{~kg}$ TNT explosion at $6 \mathrm{~m}$. The ratio of the recorded positive blast loading duration to the natural vibration period of the window specimen is $t_{d} / T_{n}=0.06$. As shown, the response mode is governed by shear responses with obvious failure at the window boundary. The deflections at the center of the window and at the window boundary do not differ significantly, especially in the vertical direction. This is more clearly observed by the deflection profiles tracked by high-speed camera shown in Figure 17. This observation indicates that when $t_{d} / T_{\mathrm{n}}$ is relatively small, the response of the window structure is governed by shear deformation. In this case, the SDOF approach defined in UFC will not give accurate predictions of the window response because it is developed with flexural response assumption, as discussed above.

Figure 18 shows the high-speed camera images of a $10 \mathrm{~mm}$ thick monolithic glass window subjected to a $10 \mathrm{~kg}$ TNT explosion at $9 \mathrm{~m}$. The $t_{d} / T_{\mathrm{n}}$ ratio of this tested specimen is 0.22 . The deflection profiles tracked from high-speed camera images are shown in Figure 19. As shown, flexural mode governs the response of this specimen. Therefore the equivalent SDOF approach is expected to give good predictions of the responses of this window structure.

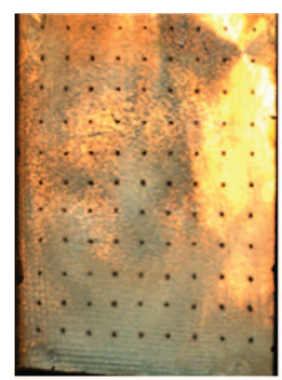

$\mathrm{t}=10 \mathrm{~ms}$

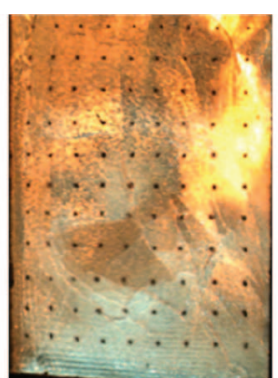

$\mathrm{t}=12 \mathrm{~ms}$

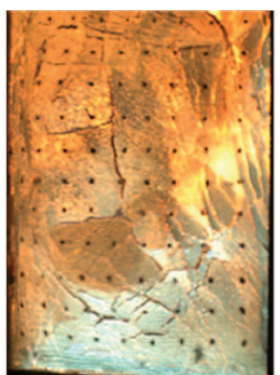

$\mathrm{t}=15 \mathrm{~ms}$

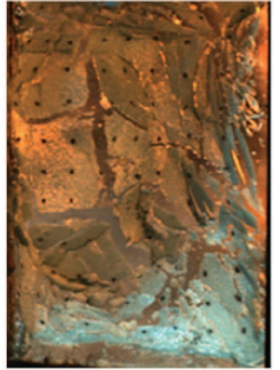

$\mathrm{t}=23 \mathrm{~ms}$

Figure 16. High-speed camera images of response process of a $6 \mathrm{~mm}$ monolithic glass window subjected to a $5 \mathrm{~kg}$ TNT explosion at $6 \mathrm{~m}$
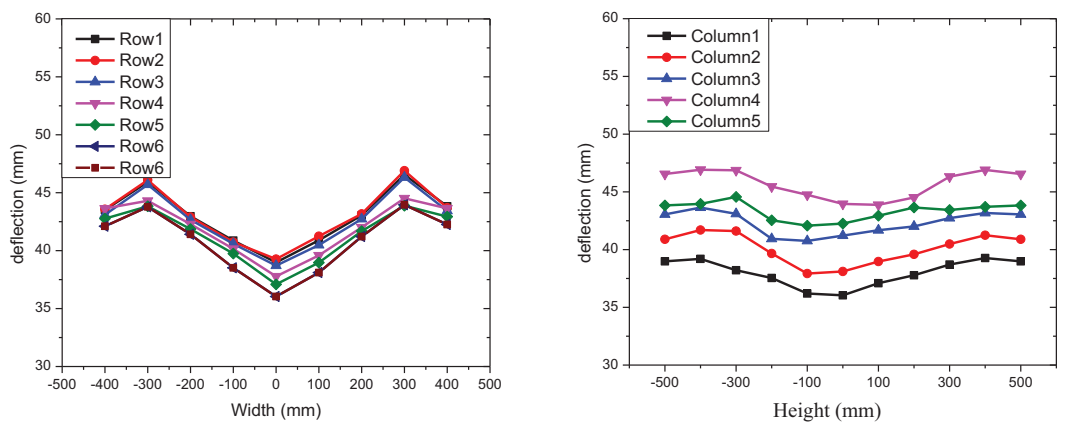

Figure 17. Deflection profiles of the $6 \mathrm{~mm}$ monolithic window tracked by high-speed camera images (32) 


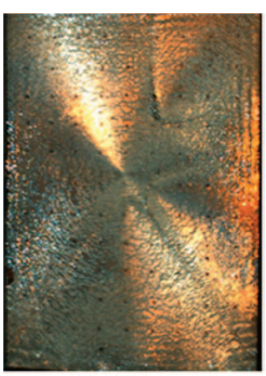

$\mathrm{t}=16 \mathrm{~ms}$

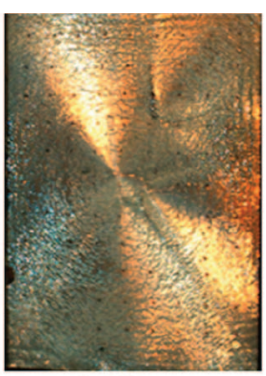

$\mathrm{t}=19 \mathrm{~ms}$

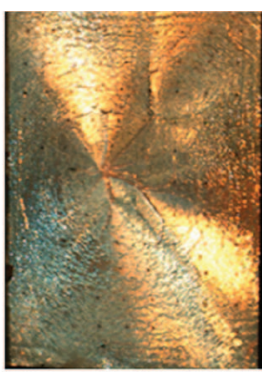

$\mathrm{t}=21 \mathrm{~ms}$

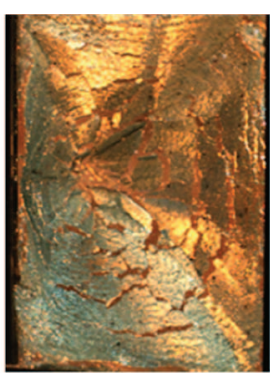

$\mathrm{t}=30 \mathrm{~ms}$

Figure 18. High-speed camera images of response process of a $10 \mathrm{~mm}$ monolithic glass window subjected to a $10 \mathrm{~kg}$ TNT explosion at $9 \mathrm{~m}$
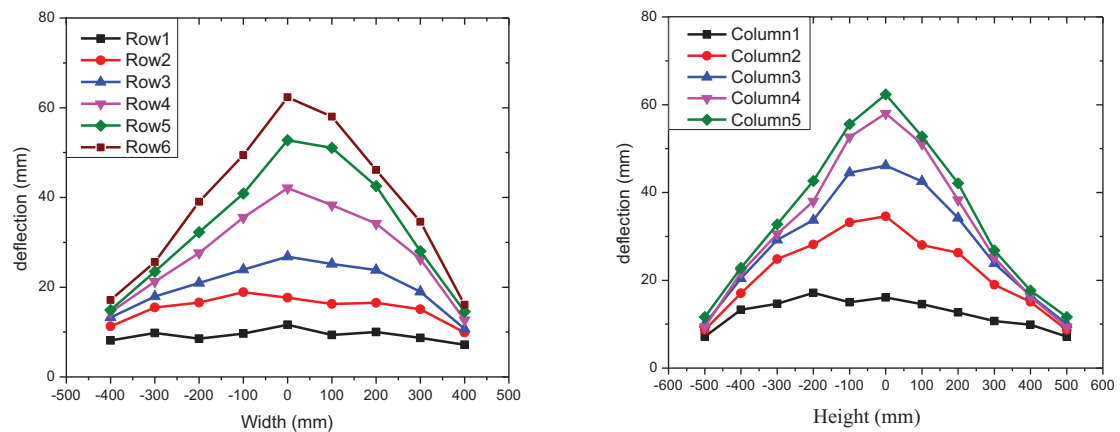

Figure 19. Deflection profiles of the $10 \mathrm{~mm}$ monolithic window tracked by high-speed camera images (32)

The above testing results demonstrate that when the standoff distance is short, the response is most likely governed by the shear mode, otherwise by the flexural mode. This is further demonstrated by the testing data of two monolithic windows subjected a $5 \mathrm{~kg}$ TNT explosion at $4.5 \mathrm{~m}$ (Figure 20a), and a $10 \mathrm{~kg}$ TNT explosion at $12 \mathrm{~m}$ (Figure 20b). These results demonstrate that depending on the standoff distance, the response can be governed by shear or flexural mode. When it is governed by shear deformation, directly using the SDOF approach in UFC will not give reliable predictions.
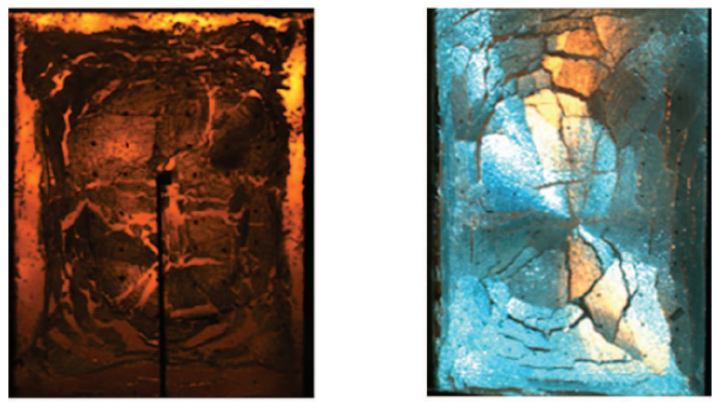

Figure 20. Two monolithic glass windows subjected to (a) $5 \mathrm{~kg}$ TNT explosion at $4.5 \mathrm{~m}$; (b) $10 \mathrm{~kg}$ TNT explosion at $12 \mathrm{~m}$ 


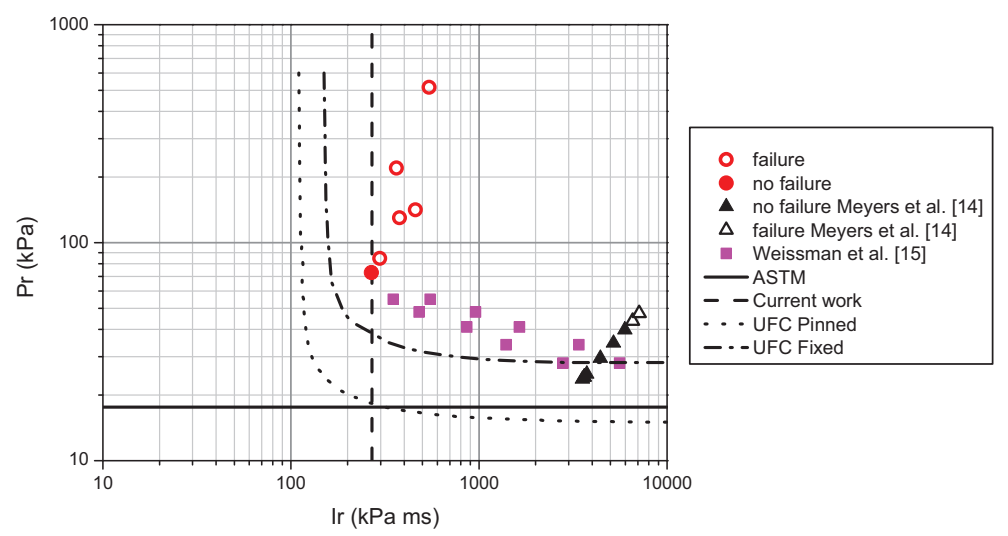

Figure 21. Comparisons of P-I diagrams generated from SDOF analyses with blast testing data (32)

This is further demonstrated by comparisons shown in Figure 21, in which the P-I diagrams of monolithic glass windows generated by SDOF analyses are compared with the field blast testing data obtained by various authors [32]. As shown, in the quasi-static response range, i.e., the response is governed by flexural mode corresponding to the relatively distant explosions the SDOF analysis gives good predictions. However, the SDOF analysis significantly underestimates the glass window capacity to resist blast loads in the impulsive range, i.e., when the blast loading duration is short and structural response is governed by brittle shear failure.

The above examples demonstrate the implications of using the SDOF analysis to predict structural responses. The SDOF model defined in [12] gives good predictions of structural responses when the response is governed by flexural mode. It cannot model local structural response, and do not give accurate predictions when the response is governed by shear deformation.

It should be noted that the classical SDOF method has been modified by various researchers to capture response mode other than flexural mode, such as compression membrane, catenary action (tension membrane), combined loading (bending and axial loading), P-delta effects, and shear response, etc. However, these modifications are not necessarily straightforward, and are not included in the design guides. Therefore they are used only by experienced engineers who have profound knowledge of structural dynamics and experiences in blast response analysis and design.

\section{DISCUSSIONS ON THE ACCURACY OF NUMERICAL ANALYSIS}

With the advancement in computational mechanics and computer power, numerical simulations with detailed FE model of structural responses subjected to blast loads have been becoming more and more popular although such simulations often require enormous computer resources and computational efforts, and are still not necessarily always affordable by many consulting firms. A number of commercial codes such as LS-DYNA and ABAQUS are available and are popularly used to predict structural responses. However, properly using those codes requires good understandings of structural dynamics, computational mechanics and dynamic material properties. Detailed discussions on those problems require significant efforts which will not be included in this paper. Here only some common problems occasionally observed in technical publications are briefly discussed. 
One common problem in developing numerical model for structural response simulation is the mesh size convergence. Quite a few computer simulations were carried out using a FE model without checking the mesh size convergence. When a structure is subjected to highrate blast loading, stress waves are generated and propagate inside the structure. These are usually modelled with explicit solver in a FE model. If the mesh size is too large, it will filter out high-frequency energies imparted from blast loading into the structure, resulting in an inaccurate prediction of the structural response. Because the blast loading energy concentrates at very high frequency band, small meshes are usually required to properly simulate structural responses. Often using very small meshes is not practical owing to high demands on computer memory and time. However, mesh size convergence check is always needed to make a reasonable compromise between simulation cost and accuracy. This is sometimes overlooked in performing numerical simulations.

Another problem is the use of inappropriate dynamic material model. Sophisticated dynamic material models for metals and normal concrete are available, and they have been proven yielding good structural response predictions. However, there is generally a lack of understanding of dynamic behaviours of many materials, such as high performance concrete, geopolymer concrete, nano concrete, glass, FRP and EPS, etc. For example, glass is generally modelled in most simulations as either a linear elastic material or by $\mathrm{JH} 2$ model. In reality, there are significant variations in glass material properties depending on the chemical components and thermal treatment. The compressive strength of glass material could vary from $200 \mathrm{MPa}$ to more than $1000 \mathrm{MPa}$. For example, a recent study [33] revealed that the compressive strain rate effect in the JH2 model is based on testing data of high-strength glass material at two strain rates only as shown in Figure 22a, and the glass is assumed to be rate insensitive under tension [34]. As shown in Figure 22, these are very different for the annealed soda-lime glass of compressive strength $236 \mathrm{MPa}$ obtained in recent SHPB tests. The glass strength in the JH2 model is also higher than that of annealed soda-lime glass. For these reasons, JH2 model does not accurately model the behavior of soda-lime glass commonly used in construction of glass windows. It should be noted that the testing results shown in Figure 22 from [33] include lateral inertial confinement effect, which is well known contributing to the strength increment in impact tests of dynamic material properties [35]. However, it was revealed in both experimental and numerical studies that the inertial confinement effect depends on the specimen size [36].

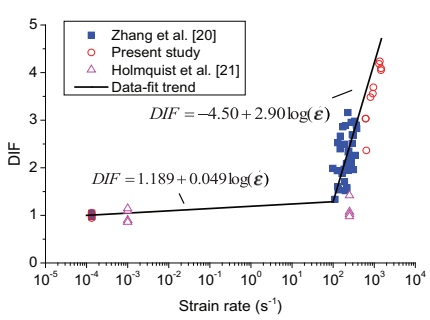

(a)

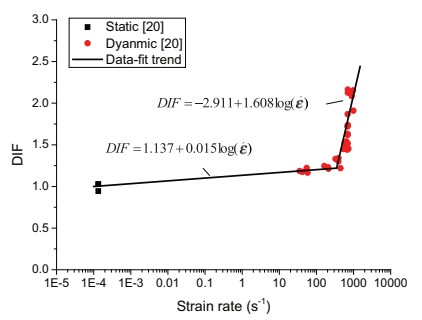

(b)

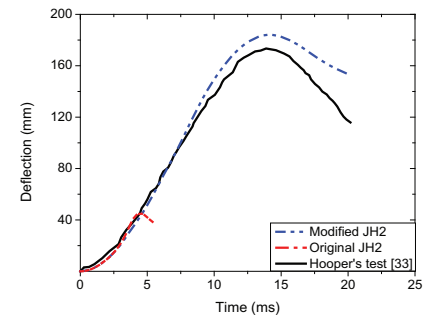

(c)

Figure 22. Comparisons of strain rate effect of annealed soda-lime glass obtained in different tests and the simulation results glass window response with testing data: (a) compressive DIF; (b) tensile DIF; (c) response subjected to blast load (33) 
The glass specimen tested has a diameter of $15 \mathrm{~mm}$, which is smaller than the normal specimen size used in SHPB tests of other materials such as concrete. Owing to the small specimen size, the lateral inertial confinement effect on strength increment is believed relatively insignificant as evidenced in [36].

Another point to note is the modelling error. A numerical model should be able to capture the fundamental structural characteristics. Otherwise the numerical predictions will not represent the true performance of a structure under blast loading. One example is the numerical model of structural progressive collapse. Structural progressive collapse in an explosion event usually occurs after the action of blast loads. Therefore it can be analyzed by removing some critical vertical load-carrying members. This approach allows one to determine if sufficient alternative load paths exist in the structure after damages to some members occur. It does not necessarily give accurate predictions of structural collapse because if blast load is large enough to knock down one structural member, the adjacent structural members are very unlikely having not suffered certain levels of damage [19]. Moreover, structural progressive collapse is not likely to start from zero initial conditions because blast loads would have imparted significant amount of energy into the structure. Moreover when progressive collapse starts, catenary effects from adjacent beams and membrane effects from connecting floors all contribute to resisting the collapse. Neglecting these contributions may greatly underestimate the structural capacity to resist progressive collapse. Using 2D frame model in predicting structural progressive collapse, as observed in some publications, is not likely leading to accurate predictions because it completely neglects the resistance from structural floor and beams in the out-of-plane direction.

\section{CONCLUSIONS}

This paper discusses the available guides and criteria for blast resistant designs and the limitations of these design guides. The differences and response characteristics of structures under blast loads and earthquake ground excitations are presented and why the experiences and criteria developed in earthquake engineering cannot be directly applied to blast engineering are explained. The limitations of using the equivalent SDOF analysis in predicting structural responses and the possible errors are discussed. The good practice in developing reliable numerical models for accurate predictions of structural responses subjected to blast loads is also outlined. The discussions presented in this paper are made because some misunderstandings have been observed in some papers published in various journals and conference proceedings. This paper is therefore prepared to clarify some fundamental features of structural responses under dynamic loadings of different loading rates so that some simple mistakes in blast resistant analysis could be avoided.

\section{ACKNOWLEDGEMENT}

The author acknowledges partial financial supports from Australian Research Council (ARC) for carrying out this research.

\section{REFERENCES}

[1] HTTP://EN.WIKIPEDIA.ORG/WIKI/2014_EAST_HARLEM_APARTMENT_BUILDINGS_ EXPLOSION, 2014.

[2] HTTP://EN.WIKIPEDIA.ORG/WIKI/LIST_OF_INDUSTRIAL_DISASTERS. 2013.

[3] US DoS. “Country reports on Terrorism 2012,” Bureau of Counterterrorism, US DoS, 2013.

[4] US DoS. “Country reports on Terrorism 2013," Bureau of Counterterrorism, US DoS, 2014. 
[5] US DoD. "UNIFIED FACILITIES CRITERIA (UFC) US DoD Antiterrorism Requirements for Buildings", Department of Defense, USA, October 2013.

[6] US Interagency Security Committee (ISC). "The Risk Management Process for Federal Facilities: An Interagency Security Committee Standard", August 2013.

[7] FEMA 430. "Site and Urban Design for Security - Guidance against potential terrorist attacks", December 2007.

[8] FEMA 428. "Primer to Design Safe School Projects in Case of Terrorist Attacks", December 2003.

[9] FEMA 426, "Reference Manual to Mitigate Potential Terrorist Attacks Against Buildings", December 2003.

[10] FEMA 427, "Primer for Design of Commercial Buildings to Mitigate Terrorist Attacks", December 2003.

[11] NATO AASTP-1 "Manual of NATO Safety Principles for the Storage of Military Ammunition and Explosives”, May 2010.

[12] UFC 3-340 02 -2008, "Structures to Resist the Effects of Accidental Explosions", US Department of Defense, 2008.

[13] TM5-855-1 "Fundamentals of Protective Design for Conventional Weapons", Department of the Army, November 1986.

[14] DoE TIC-11268, "A manual for the prediction of Blast and Fragment Loadings on Structures", U. S. Department of Energy, Albuquerque operation office, Texas, USA, 1981.

[15] ASCE, "Design of Blast Resistant Buildings for Petrochemical Facilities", Task Committee on BlastResistant Design, Second Edition, ASCE, 2010.

[16] CSA S850-12, "Design and assessment of buildings subjected to blast loads", Canadian Standards Association, ON, Canada, 2012.

[17] UFC 4-023-03, "Design of Buildings to Resist Progressive Collapse”, US Department of Defense, 2005.

[18] GSA, "Progressive Collapse Analysis and Design Guidelines for New Federal Office Buildings and Major Modernization Projects", US General Services Administration, 2000.

[19] Shi, Y.C., Li, Z.X. and Hao, H., "A New Method for Progressive Collapse Analysis of RC Frames under Blast Loading”, International Journal of Engineering Structures, Vol. 32, 2010, pp. 1691-1703.

[20] Gebbeken, N. and Doge, T., "Explosion protection - architectural design, urban planning and landscape planning”, International Journal of Protective Structures, Vol. 1(1), 2010, pp. 1-21.

[21] Zhou, X.Q. and Hao, H., "Prediction of blast loads on structures behind a protective barrier", International Journal of Impact Engineering, Vol. 35, 2008, pp. 363-375.

[22] Baker, W.E., Cox, P., Kulesz, J., Strehlow, R. and Westine, P. "Explosion hazards and evaluation”, Elsevier, 1983.

[23] Van den Berg, A., "The multi-energy method: a framework for vapour cloud explosion blast prediction". Journal of hazardous material, 12(1), 1985, pp. 1-10.

[24] Bjerketvedt, D., Bakke, J.R. and Van Wingerden, K, "Gas explosion handbook". Journal of hazardous material, 52(1), 1997, pp. 1-150.

[25] Dewey, J.M., "The TNT equivalence of an optimum propane-oxigen mixture". Journal of Phys D: Appl Phys., Vol. 38, 2005.

[26] Standards Australia, "Structural Design Actions Part 4: Earthquake actions in Australia.” Sydney, Australia, 2007.

[27] SEAOC, "Vision 2000: Performance Based Seismic Engineering of Buldings." California Office of Emergency Services, 1995.

[28] Biggs, J.D., "Introduction to Structural Dynamics", McGraw Hill Publishing Company, New York, USA, 1964.

[29] Oswald, C. and Bazan, M., "Comparison of SDOF analysis results to test data for different types of blast loaded components", Online http://www.protection-consultants.com/uploads/SEI\%20Congress\%202014_ SDOF_Final_689.pdf, 2014.

[30] Salim, H.A., Dinan, R., Kiger, S.A., Townsend, P.T. and Shull, J., "Blast Retrofit Wall Systems Using Cold-Formed Steel Studs," The 16th ASCE Engineering Mechanics Conference, University of Washington, July 16-18, 2003.

[31] Crawford, J.E. and Magallanes, J.M., "The effects of modelling choices on the response of structural components to blast effects". International Journal of Protective Structures, 2(2), 2011, pp. 231-266. 
[32] Zhang, X., Hao, H. and Wang, Z., "Experimental investigation on monolithic tempered glass window responses to blast loads', International Journal of Protective Structures, Vol. 6(2), 2015, pp. 287-310.

[33] Zhang, X., Hao, H. and Ma, G.W., "Dynamic material model of annealed soda-lime glass", International Journal of Impact Engineering, Vol. 77, 2015, pp. 108-119.

[34] Holmquist, T.J., Johnson, G.R., Lopatin, C., Grady, D. and Hertel Jr, E.S., "High strain rate properties and constitutive modeling of glass". 15th International Symposium on Ballistics, Jerusalem, Israel, 1995.

[35] Yifei Hao and Hong Hao, "Influence of Aggregates on Concrete Compressive Strength at High strain rate", International Journal of Protective Structures, Vol. 2 (2), 2011, pp. 177-206.

[36] Yifei Hao, Hong Hao, Guoping Jiang. and Yun Zhou, "Experimental confirmation of some factors influencing dynamic concrete compressive strengths in high-speed impact tests", Cement and Concrete Research, Vol. 52, 2013, pp. 63-70. 
